\title{
A Comprehensive Assessment of the Person-Environment Fit Dimensions and Their Relationships With Work- Related Outcomes
}

Journal of Career Development 2019, Vol. 46(5) 567-582

(C) Curators of the University of Missouri 2018

Article reuse guidelines: sagepub.com/journals-permissions DOI: $10.1177 / 0894845318789512$ journals.sagepub.com/home/jcd

(SAGE

\section{Marie Andela', and Margot van der Doef ${ }^{2}$}

\begin{abstract}
Our aim was to better understand the relationship between person-environment fit (PE fit) and several work-related outcomes, that is, burnout, job satisfaction, and turnover intention. To achieve this goal, direct effects of PE fit on these variables were explored as well as the indirect effects of PE fit on turnover intention through burnout and job satisfaction. The study was conducted on an occupationally heterogenous sample of $57 \mathrm{I}$ employees in France. Four types of fit were taken into account (person-job fit [PJ fit], person-organization fit [PO fit], person-group fit [PG fit], and personsupervisor fit [PS fit]). Correlations, regression, and mediation analyses were performed. Results indicated that the four dimensions of PE fit were positively related to job satisfaction and negatively associated with burnout and turnover intention. PJ fit and PO fit were more strongly correlated with these three work-related outcomes than PG fit and PS fit. Mediation analyses indicated that job satisfaction fully mediated the relationship between PJ fit, PO fit, PS fit, and turnover intention, while burnout partially mediated these relationships.
\end{abstract}

\section{Keywords}

person-environment fit, burnout, turnover intention, job satisfaction

\footnotetext{
'Laboratoire de psychologie, Université de Bordeaux, Bordeaux, France

${ }^{2}$ Health, Medical and Health Psychology Unit, Institute of Psychology, Leiden, the Netherlands
}

Corresponding Author:

Marie Andela, Laboratoire de psychologie, Universite de Bordeaux, 3 ter Place de la Victoire, Bordeaux Cedex, Aquitaine 33076, France.

Email: marie.andela@u-bordeaux.fr 
Broadly defined as "the compatibility between an individual and a work environment that occurs when the characteristics are well matched" (Kristof-Brown, Zimmerman, \& Johnson, 2005, p. 281), the person-environment fit (PE fit) approach states that a fit between the person and the environment results in positive outcomes (e.g., job satisfaction, job performance), while their misfit produces psychological, physiological, and behavioral strains (e.g., dissatisfaction, burnout; Edwards \& Shipp, 2007; Kristof-Brown et al., 2005). As a result, the PE fit concept has received growing interest among organizational researchers and practitioners (Kristof-Brown, 2000). Researchers have started to conceptualize the different components of fit and recent theoretical perspectives agree to define the PE fit concept as multidimensional (Edwards \& Billsberry, 2010; Jansen \& Kristof-Brown, 2006; Wheeler, Buckley, Halbesleben, Brouer, \& Ferris, 2005). Four types of fit have been defined, covering the main components of employees' work environment (KristofBrown et al., 2005; Kristof-Brown \& Guay, 2011): person-job (PJ fit), person-organization (PO fit), person-group ( $P G$ fit), and person-supervisor ( $P S$ fit). Although the multidimensionality of $\mathrm{PE}$ fit is widely agreed upon, studies that analyzed the joint effects of PE dimensions on workrelated outcomes are scarce and have generally used different measurements which were not based on the same development and validation procedures. Thus, the first aim of the present study was to examine simultaneously the relationship of the four dimensions of PE fit with three work-related outcomes relevant within the context of I/O psychology: job satisfaction, burnout, and turnover intention. Moreover, to gain more insight in the relationship between PE fit and these three workrelated outcomes, our second aim was to examine the potential mediating role of burnout and job satisfaction in the association between PE fit and turnover intention.

\section{PE Fit: A Multidimensional Concept}

The origins of the PE fit concept can be found in various theories such as Murray's need-press model (Murray, 1938), Lewin's field theory (Lewin, 1951), and French, Rodgers, and Cobb's model (1974). This last model defined adjustment as the goodness of fit between the person and his or her environment by adding that PE fit can refer to the subjective as well as the objective person and environment. Based on this theory, PE fit became a core concept in research on job satisfaction (Katzell, 1964; Locke, 1976) and job stress (French, Caplan, \& Harrison, 1982; McGrath, 1976). Although much research has been conducted regarding PE fit (see Kristof-Brown et al., 2005, for a review), there are issues that require further clarification.

\section{The experience of fit cannot be reduced to a single dimension}

Indeed, while much emphasis has been placed on the match between people's interests and those of others in a vocation (e.g., Holland, 1985), other types of fit, such as an individual's compatibility with his or her job, organization, work group, and supervisor have also emerged as important research domains. These different types of fit fell under the umbrella of the PE fit, and the field has long been criticized as it remained generally unclear about the construct of fit until the theorization of PE fit as a multidimensional construct (Edwards \& Billsberry, 2010; Jansen \& Kristof-Brown, 2006; Wheeler et al., 2005). In fact, the individual is nested in multiple aspects of an environment and as a consequence the experience of fit cannot be reduced to a single dimension. Thus, several studies indicated that focusing on only one type of fit provided an incomplete picture of PE fit (Ostroff, Shin, \& Kinicki, 2005). Moreover, it has been argued that in many studies, only a very limited number of content dimensions of each type of fit was assessed (Edwards \& Cooper, 1990). As a result, the multiple content dimensions (e.g., values, goals, personality, and interests) of each dimension of PE fit were not taken into account. Thus, reviews on the impact of fit on employees work-related outcomes could not distinguish between PJ fit and PO fit and paid little attention to the more recent dimensions PG fit or PS 
fit (Kristof-Brown et al., 2005). Moreover, researchers also pointed out that explorations of how poor fit influences psychological variables, such as strain and burnout, were lacking and are needed to identify explanatory mechanisms to better understand the fit-outcome relationships (Scherer, Allen, \& Harp, 2016). To our knowledge, no study has thus far used a comprehensive PE fit assessment including the four subdimensions of fit to investigate the relationships between these four subdimensions of fit and employees' burnout.

The four dimensions of PE fit. Based on the current definition and conceptualization of PE fit (Chuang, Shen, \& Judge, 2016; Kristof-Brown et al., 2005; Kristof-Brown \& Guay, 2011), the present study incorporates the following four subdimensions of PE fit. PJ fit refers to the compatibility between an individual and a specific job (Chuang et al., 2016; Kristof-Brown et al., 2005). The PJ fit consists of two forms of fit: The first is the demands-abilities fit, which is the fit between the abilities of the employee and the job requirements. The second form of fit is the needs-supplies fit, that is, the match between the person needs, desires, and preferences and the supplied attributes of a job. PO fit is defined as the compatibility between individual and organizational characteristics in terms of values and goals (Chuang et al., 2016). PG fit or person team fit refers to the interpersonal compatibility between individuals and their work group members (Chuang et al., 2016; Kristof-Brown et al., 2005). The interpersonal compatibility includes PG personality fit, values fit (Seong \& Kristof-Brown, 2012), goals fit (Kristof-Brown \& Stevens, 2001), and work style fit (Kristof-Brown, Jansen, \& Colbert, 2002). The match between the person and the group on these levels is considered to facilitate the collaboration among employees. PS fit is defined as the match between supervisor(s) and subordinates (KristofBrown et al., 2005; Van Vianen, 2000). Based on the previous research, Chuang, Shen, and Judge (2016) conceptualize PS fit by including values, personality, work style, life style, and leadership style. Generally, people are attracted to others on the basis of similarity regarding personality, goals, and values (Chuang et al., 2016). Thus, supervisor(s) and subordinates who experience such similarities are considered to have a good PS fit.

\section{PE Fit, Burnout, Job Satisfaction, and Turnover Intention}

In the present study, we relate these four fit dimensions to three work-related outcomes: burnout, job satisfaction, and turnover intention. Employee's burnout is a progressive psychological response to chronic work stress and involves emotional exhaustion (EE), depersonalization, and feelings of reduced professional efficacy (Maslach \& Jackson, 1981). Turnover intention, regarded as the final step of withdrawal behavior (e.g., Tett \& Meyer, 1993), is defined as an employee's desire to leave the organization (Mobley, Horner, \& Hollingsworth, 1978).

PE fit and work-related outcomes from a theoretical perspective. From a conceptual standpoint, job satisfaction, burnout, and turnover intention have strong links to PE fit, given that many theories of stress and job satisfaction implicitly or explicitly incorporate PE fit as central concepts (Edwards \& Shipp, 2007). Stress is defined in terms of the interaction between the person and the situation: Stress appears when demands tax or exceed the abilities or resources of the person (Lazarus \& Folkman, 1984) or when intrinsic or extrinsic rewards of the situation fall short of the needs, desires, or goals of the person (Cummings \& Cooper, 1979). These definitions of stress match with the PE fit theory of stress (French et al., 1982; Harrison, 1978), which defines stress as misfit between subjective needs and environmental supplies. As well as relational stress theory, discrepancy theories of job satisfaction are very close to the domain of PE fit. Indeed, discrepancy theories of job satisfaction suggest that job satisfaction results from the comparison between what the job provides and what the employee needs, wants, or desires from the job (Edwards \& Shipp, 2007). This comparison corresponds to the needs-supplies fit conceptualization as discussed in the PE fit literature. 
PE fit and work-related outcomes from an empirical perspective. In line with this theoretical background, empirical studies have confirmed the positive association between the four dimensions of fit (PJ fit, PO fit, PG fit, and PS fit) and job satisfaction (Cable \& DeRue, 2002; T. Y. Kim, Aryee, Loi, \& Kim, 2013; McCulloch \& Turban, 2007; Ostroff et al., 2005; Vancouver \& Schmitt, 1991). Furthermore, empirical studies have confirmed the negative relationship between job-person fit and job strain (Kristof-Brown et al., 2005) and turnover intention (Wang, Zhan, McCune, \& Truxillo, 2011). The limited research done on burnout, indicated that PO fit was associated with burnout (Pyhältö, Pietarinen, \& SalmelaAro, 2011; Shanafelt et al., 2009; Tong, Wang, \& Peng, 2015). Empirical evidence has also been provided for the association between PO fit and turnover intention (Wang et al., 2011) and employee retention (McCulloch \& Turban, 2007).

As mentioned above, PG fit and PS fit, which are the most recent dimensions added to the PE fit concept, have not yet gained as much attention as the PJ fit or the PO fit. To our knowledge, no study has investigated the relationships between these two dimensions of fit with employees' burnout. Thus, we aim to explore these relationships in the present study. In view of these findings regarding the impact of PE fit on work-related outcomes, we propose the following hypothesis:

Hypothesis 1: The four dimensions of fit (PJ fit, PO fit, PG fit, and PS fit) will be negatively related to burnout and turnover intention and positively related to job satisfaction

Moreover, to our knowledge, with the exception of Chuang et al. (2016) research, no study used a comprehensive PE fit assessment including all four subdimensions of fit to investigate their relative contribution to several work-related outcomes. The relevance of the present study is to add on to the study of Chuang et al. (2016) by testing our hypotheses in another cultural context and by including burnout, as a work-related outcome, which was not taken into account in their study. As such, this study determines the relative amount of explained variance of all four subdimensions of fit in burnout, job satisfaction, and turnover intention and assesses the potential differential effects of the four PE dimensions on these work-related outcomes.

\section{PE Fit and Turnover Intention: The Mediating Role of Burnout and Job Satisfaction}

Beyond the direct effects of PE fit on job satisfaction, burnout, and turnover intentions, we also examine the indirect effects of PE fit on turnover intention through burnout and job satisfaction. More precisely, to gain more insight in the relationship between the variables under study, our second aim was to explore the nature of the relationship of the four types of fit and turnover intention by analyzing the mediating role of burnout and job satisfaction. Inspired by the job demands-resources model (Bakker \& Demerouti, 2007), we expect PE fit to exert its effects on turnover intention through two pathways: a health impairment and a motivational pathway. These pathways have been described to indicate the way in which job demands and job resources exert their influence on organizational outcomes, such as absenteeism, turnover, and performance. Various studies have found that indicators of health impairment (e.g., burnout) and indicators of motivation (e.g., work engagement) predict these organizational outcomes. For instance, in the study from Bakker, Demerouti, de Boer, and Schaufeli (2003), burnout and organizational commitment predicted absenteeism, whereas in the study from Kraemer and Gouthier (2014) EE and organizational pride predicted turnover intention. We expect a PE misfit to exert its impact on turnover intention through similar pathways where misfit results on the one hand in reduced motivation-reflected by lower job satisfaction-and on the other hand health impairment—reflected by higher burnout. 


\section{The mediating role of job satisfaction}

Empirical evidence suggests a direct effect of job satisfaction on intention to leave the job: When employees are satisfied with their jobs, they are committed to the organization (Agho, Price, \& Mueller, 1992; Cheung \& Tang, 2007; Lok \& Crawford, 2001). Besides this direct effect, several studies have also reported that job satisfaction was mediating the relationship between PJ fit, PO fit, and intentions to leave (Wheeler et al., 2005; Wheeler, Gallagher, Brouer, \& Sablynski, 2007). These results suggest that poor PJ fit and PO fit lead to dissatisfaction, which ultimately results in intentions to leave. Based on these findings, we propose the following hypothesis:

Hypothesis 2: Job satisfaction will mediate the relationship between the four dimensions of PE fit and turnover intention.

The mediating role of burnout. The positive direct relationship between employee's burnout and turnover intention has been empirically supported in various business contexts (H. Kim \& Stoner, 2008; Lu \& Gursoy, 2016; Schaufeli \& Bakker, 2004). The relationship between burnout and turnover intention was found to be significant in studies conducted among nursing staff (Leiter \& Maslach, 2009), service workers, and correctional staff (Griffin, Hogan, Lambert, Tucker-Gail, \& Baker, 2010). Today, scholars generally agree that EE predicts turnover intentions positively (Lee \& Ashforth, 1993; Wright \& Cropanzano, 1998). Moreover, several studies have provided evidence that burnout plays a mediating role in the relationship between job stressors and employee turnover (Han, Bonn, \& Cho, 2016; Hinkin $\&$ Tracey, 2000). For example, in a study on 667 Canadian nurses, Leiter and Maslach (2009) found burnout played a mediating role between incongruities and turnover intentions. In this study, incongruities were described as mismatches between the person and the job concerning six areas of work life: workload, control, reward, community, fairness, and values. Organizational work life mismatch is indeed predictive of levels of burnout, which in turn are predictive of turnover intention (Leiter $\&$ Maslach, 2009). Based on these findings, we suggest the following hypothesis:

Hypothesis 3: Burnout will mediate the relationship between the four dimensions of PE fit and turnover intention.

\section{Method}

\section{Participants and Procedure}

The study includes an occupationally heterogeneous sample to test our hypotheses. Our sample was composed of employees working in different organizations in the service sector in France (i.e., 14\% from schools, $19 \%$ from hospitals, $28 \%$ from commercial companies, and $39 \%$ from hospitality industries) and included 571 employees ( $n=326$ women; $n=245$ men) from a broad range of professional groups: nurses, nurses' assistants, teachers, hospitality workers, and secretaries. Participants worked on average $35 \mathrm{hr}$ per week. The sample was predominantly French (99.5\%), and the average age of participants was 37 years $(S D=13$, range $=18-64)$. For each organization, a contact person was identified and asked to send an invitation to participate to our study to other colleagues. The study was presented as a research concerning the relationship between the person and its work-environment and several work-related outcomes. The invitation was sent by each identified contact person via an e-mail containing a link leading to an online survey. The condition to participate to the study consisted in working in an organization within a team group, having a supervisor and working more than $30 \mathrm{hr}$ per week. Thus, the size of the participants' work organizations was middle or large. Participation was anonymous and no information that could be used to identify participants was requested. 


\section{Measures}

PE fit was measured with the Perceived Person-Environment Fit Scale which consists of four dimensions (Chuang et al., 2016): Person-Job Fit Scale (PJFS), Person-Organization Fit Scale (POFS), Person-Group Fit Scale (PGFS), and Person-Supervisor Fit Scale (PSFS). The PJFS (4 items) consists of demands-abilities fit and the needs-supplies fit (e.g., "How would you describe the match between your professional skills, knowledge, and abilities and those required by the job?"). The POFS consists of two subscales including values and goals which are operative in the workplace with a comparative emphasis scale: POFS values ("How would you describe the match between your emphasis and your organization's emphasis on the following values?" i.e., honesty, achievement, fairness, and helping others) and POFS goals ("How would you describe the match between your goals and your organization's goals on the following dimensions? e.g., reward, the amount of effort expected, and competition with other organizations). The PGFS includes 10 items that refer to three subscales covering the content dimensions of values, goals, and member attributes: PGFS values ("How would you describe the match between your emphasis and your group's emphasis on the following values?" i.e., honesty, achievement, fairness, and helping others), PGFS goals ("How would you describe the match between your goals and your group's goals on the following dimensions?" i.e., reward, the amount of effort expected, and competition with other organizations), and PGFS attributes ("How would you describe the match between you and your group members on the following characteristics?" i.e., personality, work style, and lifestyle). The PSFS includes 5 items comprising the content dimensions of values, personality, work style, lifestyle, and leadership style ("How would you describe the match between the things you value in life and the things your superior values?"; "How would you describe the match between your personality and your supervisor's personality?"). All items were scored on a 7-point Likert-type scale $(1=$ no match; $7=$ complete match $)$. The internal consistency of each subscale was satisfactory in our study (PJFS for $\alpha=.75$, POFS for $\alpha=.82$, PGFS for $\alpha=.87$, and PSFS for $\alpha=.86$ ). These scores were in line with previous findings reporting that the scale scores have adequate evidence for reliability (PJFS for $\alpha=.89$, POFS for $\alpha=.93$, POFS for $\alpha=.91$, and PSFS for $\alpha=.91$ in Chuang et al., 2016) and construct validity, correlating in expected directions with scores on job satisfaction, job performance, and turnover intention (Chuang et al., 2016).

Burnout was measured with the Maslach Burnout Inventory-General Survey (MBI-GS), which contains three subscales (Schaufeli, Leiter, Maslach, \& Jackson, 1996). EE subscale (5 items) assesses feelings of being exhausted by one's work (e.g., "I feel tired when I get up in the morning and have to face another day on the job"). Cynicism (CY) subscale (5 items) refers to distancing oneself from work itself and to the development of negative attitudes toward work in general (e.g., "I have become more cynical about whether my work contributes anything"). Professional efficacy subscale (6 items) assesses (e.g., "I feel I am making an effective contribution to what this organization does"). All items are scored on a 7-point Likert-type scale, ranging from 0 (never) to 6 (every day). The Cronbach's $\alpha$ reliability was satisfactory for each subscale (EE for $\alpha=.81 \mathrm{for}$; CY for $\alpha=.74$; and PE for $\alpha=.73$ ). The MBI-GS scales scores have adequate evidence for factorial validity: Exploratory factor analysis and confirmatory factor analysis confirmed the factorial validity in eight different occupational groups of employees ( $N=2,919$ in Bakker, Demerouti, \& Schaufeli, 2002).

Job satisfaction was measured with Job Satisfaction scale validated by Fouquereau and Rioux (2002). The scale consists of 5 items (e.g., "I am satisfied of my professional life") and rated on 7-point Likert-type scale, ranging from 1 (strongly disagree) to 7 (strongly agree). The Cronbach's $\alpha$ reliability was satisfactory $(\alpha=.88)$. This score was in line with previous findings that have demonstrated strong evidence for test-retest reliability and internal consistency reliability ( $\alpha=$ .87 in Fouquereau and Rioux [2002]). Job satisfaction has also received support for convergent validity based on their correlations with satisfaction scale as the Minnesota Satisfaction Questionnaire (Fouquereau \& Rioux, 2002). 
Table I. Means, Standard Deviations, Reliabilities, and Intercorrelations of the Variables Under Study.

\begin{tabular}{|c|c|c|c|c|c|c|c|c|c|c|}
\hline Means & $S D$ & 1 & 2 & 3 & 4 & 5 & 6 & 7 & 8 & 9 \\
\hline I. PJ fit & 19.25 & 4.46 & $(.75)$ & & & & & & & \\
\hline 2. PO fit & 32.96 & 7.71 & $.59 * *$ & $(.82)$ & & & & & & \\
\hline 3. PG fit & 46.34 & 10.32 & $.47^{* *}$ & $.7 I^{* *}$ & $(.87)$ & & & & & \\
\hline 4. PS fit & 19.54 & 6.97 & $.36 * *$ & $.48 * *$ & $.49 * *$ & $(.86)$ & & & & \\
\hline 5. Job satisfaction & 21.11 & 7.21 & $.65 * *$ & $.61^{* *}$ & $.46 * *$ & $.49 * *$ & $(.88)$ & & & \\
\hline $\begin{array}{l}\text { 6. Emotional } \\
\text { exhaustion }\end{array}$ & 16.32 & 6.73 & $-.35 * *$ & $-.40 * *$ & $-.29 * *$ & $-.28 * *$ & $-.48^{* *}$ & $(.8 \mathrm{I})$ & & \\
\hline 7. Cynicism & 14.70 & 6.81 & $-.43 * *$ & $-.50 * *$ & $-.39 * *$ & $-.40 * *$ & $-.58 * *$ & $.59 * *$ & $(.74)$ & \\
\hline 8. Professional efficacy & 9.48 & 5.99 & $.4 I^{* *}$ & $.32^{* *}$ & $.27 * *$ & $.27^{* *}$ & $.42^{* * *}$ & $-.17^{* *}$ & $-.26 * *$ & $(.73)$ \\
\hline 9. Turnover intention & 11.81 & 3.54 & $-.49 * *$ & $-.48 * *$ & $-.38^{* *}$ & $-.39 * *$ & $-.67 * *$ & $.45 * *$ & $.65^{* *}$ & $-.33 * *(.89)$ \\
\hline
\end{tabular}

Note. ()$=$ Cronbach's $\alpha$ coefficients of each scale are reported on the diagonal. PJ fit = person-job fit; PO fit $=$ personorganization fit; PG fit = person-group fit; PS fit = person-supervisor fit. $*_{p}<.05 . * * p .01$.

Turnover intention was evaluated with 3 items created by O'Reilly, Chatman, and Caldwell (1991) and used in the study of Lauver and Kristof-Brown (2001). Items include "I would prefer another job to the one I have now"; "If I have my way, I won't be working for this company a year from now"; and "I have seriously thought about leaving this company." Items were rated on a 7-point Likert-type scale, ranging from 1 (strongly disagree) to 7 (strongly agree). The Cronbach's $\alpha$ reliability was satisfactory $(\alpha=.89)$. The scale scores have adequate evidence for reliability $(\alpha=.85$ in Lauver and KristofBrown [2001]) and construct validity, correlating in expected directions with scores on job satisfaction, PJ fit, and PO fit (Lauver \& Kristof-Brown, 2001).

\section{Data Analysis}

To test the direct relationship between PE fit (PJ fit, PO fit, PG fit, and PS fit), burnout, turnover intention, and job satisfaction (Hypothesis 1), bivariate correlations were computed. To assess the relative importance of the different subdimensions of the PE fit and these work-related outcomes, one multiple regression analysis per outcome was performed. In each analysis, in the first step, we controlled for age, gender, and type of occupation, to avoid confounding effects by these background variables. PJ fit, PO fit, PG fit, and PS fit were then entered in the second step of the regression analyses. All variables were centered before entering them into a regression analysis.

With regard to mediation analysis, current methods have moved beyond the causal steps approach (multistep regression model), popularized by Baron and Kenny (1986), to a more robust approach that can quantify rather than simply infer the indirect effect (Hayes, 2009). Thus, to adequately test the mediating role of job satisfaction and burnout (Hypotheses 5 and 6), we used the SPSS Version 25 macro PROCESS developed by Hayes and Preacher. Mediation analysis tests whether the effects of an independent variable on an outcome variable can be accounted for by its effect on a mediator variable, which in turn affects the outcome.

\section{Results}

\section{Intercorrelations}

As reported in Table 1, intercorrelations between each dimension of the PE fit were as follows: PJ fit and PO fit $(r=.59, p<.01)$, PJ fit and PG fit $(r=.47, p<.01)$, PJ fit and PS fit $(r=.36, p<.01)$, PO fit 
Table 2. Burnout, Job Satisfaction, and Turnover Intention Regressed on the Person-Environment Fit Dimensions, Controlling for Gender, Age, and Profession.

\begin{tabular}{|c|c|c|c|c|c|}
\hline Variables Under Study & $\begin{array}{l}\text { Emotional } \\
\text { Exhaustion }\end{array}$ & Cynicism & $\begin{array}{c}\text { Professional } \\
\text { Efficacy }\end{array}$ & $\begin{array}{c}\text { Job } \\
\text { Satisfaction }\end{array}$ & $\begin{array}{l}\text { Turnover } \\
\text { Intention }\end{array}$ \\
\hline \multicolumn{6}{|l|}{ Step I } \\
\hline Gender & -.04 & -.06 & -.07 & -.00 & -.06 \\
\hline Age & -.03 & -.04 & -.04 & .03 & $-.14 * *$ \\
\hline Profession & .05 & .03 & .03 & .04 & .05 \\
\hline$R^{2}$ & .00 & .00 & .00 & .00 & $.02 *$ \\
\hline \multicolumn{6}{|l|}{ Step 2} \\
\hline Person-job fit & $-.16 * *$ & $-.19 * *$ & $.33 * *$ & $.42 * *$ & $-.30 * *$ \\
\hline Person-organization fit & $-.29 * *$ & $-.31 * *$ & .06 & $.31 * *$ & $-.23 * *$ \\
\hline Person-group fit & .04 & .01 & .01 & -.06 & .01 \\
\hline Person-supervisor fit & $-.10 *$ & $-.18 * *$ & $.12 * *$ & $.22 * *$ & $-.18 * *$ \\
\hline$R^{2}$ full model & $.19 * *$ & $.30 * *$ & $.19 * *$ & $.54 * *$ & $.35^{* *}$ \\
\hline
\end{tabular}

$* p<.05 . * * p<.01$.

and PG fit $(r=.71, p<.01)$, PO fit and PS fit $(r=.48, p<.01)$, and PG fit and PS fit $(r=.49, p<.01)$. These intercorrelations were similar to the results found in the validation of the original scale (Chuang et al., 2016). The correlation between PO fit and PG fit was equally high in their sample $(r=.71$, $p<.01)$. The means and standard deviations reported in Table 1 indicated sufficient variance in the data for the PE fit dimensions.

\section{Correlations Between the Four PE Fit Dimensions and Work-Related Outcomes}

We first hypothesized that the four PE fit dimensions would be negatively related to burnout and turnover intention and positively related to job satisfaction. Correlation analysis (see Table 1) indicated that the four dimensions of fit were negatively related to EE, CY, and turnover intention, while they were positively associated with professional efficacy and job satisfaction. Thus, results were in line with our first hypothesis.

\section{Relative Importance of the Four Dimensions of PE Fit for Burnout, Job Satisfaction, and Turnover Intention}

Hierarchical regression analyses were conducted to assess the relative importance of the different dimensions of PE fit for the work-related outcomes under study.

The hierarchical regression analyses included participants' gender, age, profession, and the four dimensions of the PE fit. This model was statistically significant for all five outcomes and accounted for $19 \%$ of the variance of EE, $30 \%$ of the variance of CY, $19 \%$ of the variance of professional efficacy, $54 \%$ of the variance of job satisfaction, and $35 \%$ of the variance of turnover intention.

First of all, gender, age, and profession were entered in the first step of the regression analysis (see Table 2). Controlling for these variables in Step 1, results indicate that gender, profession, and age were not related to burnout or job satisfaction. Age was however negatively related to turnover intention $(\beta=-.14, p<.01)$, indicating lower turnover intention among the older employees. The four dimensions of PE fit were introduced in the second step (see Table 2). Results of the regression analyses confirm the correlational results, highlighting the strong relationships of PJ fit and PO fit with the outcomes burnout, job satisfaction, and turnover intention. PJ fit and PO fit were the most predictive components for the work-related outcomes under study. Indeed, burnout and turnover intention were 


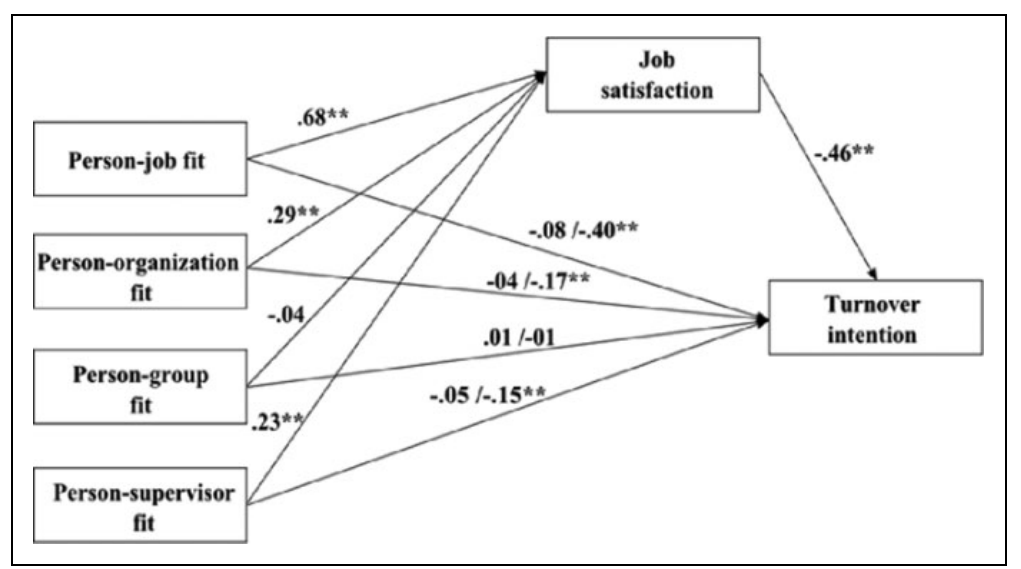

Figure I. The mediating role of job satisfaction.

primarily related with low levels of PJ fit and PO fit, and to a lesser extent to PS fit. However, differential effects can be observed: PO fit primarily predicted EE and CY, whereas PJ fit mainly predicted professional efficacy, job satisfaction, and turnover intention.

\section{PE Fit and Turnover Intention: The Mediating Role of Job Satisfaction}

The correlations reported in Table 1 indicate that the four predictor variables (PJ fit, PO fit, PG fit, and PS fit) and job satisfaction were significantly associated with turnover intention. As such, further examination of potential mediation effects is appropriate. Figure 1 shows the results of the mediation analysis for job satisfaction. Table 3 shows the direct and indirect effects for turnover intention with and without job satisfaction as a mediator variable. The table reports $95 \%$ bias corrected bootstrapped confidence interval. Given the finding when zero is not included in the $95 \%$ interval a significant indirect effect is apparent.

In the direct effect model with job satisfaction as a mediator (see Figure 1), job satisfaction was strongly related to turnover intention. With job satisfaction in the model, PJ fit, PO fit, and PS fit were no longer significantly associated with turnover intention. This mediation effect is confirmed when testing the indirect effect (see Table 3), with significant indirect effects of PJ fit, PO fit, and PS fit on turnover intention through job satisfaction. We can thus conclude that job satisfaction mediates the effects of PJ fit, PO fit, and PS fit on turnover intention. No mediation through job satisfaction was apparent for PG fit, as this PE fit dimension was not significantly related to job satisfaction and turnover intention. Thus, Hypothesis 2 was supported except for the PG fit dimension.

\section{PE Fit and Turnover Intention: The Mediating Role of Burnout}

The correlations reported in Table 1 indicate that the four predictor variables (PJ fit, PO fit, PG fit, and PS fit) and the three burnout dimensions (EE, CY, and low personal accomplishment) were significantly associated with turnover intention. As such, further examination of potential mediation effects was appropriate. In the direct effect models with EE, CY, and professional efficacy as mediators, the three burnout dimensions were related to turnover intention. While EE and CY were strongly associated with turnover intention, higher professional efficacy was related to lower turnover intention. Table 3 presents the effects for turnover intention with and without EE, CY, and professional efficacy as mediators. 


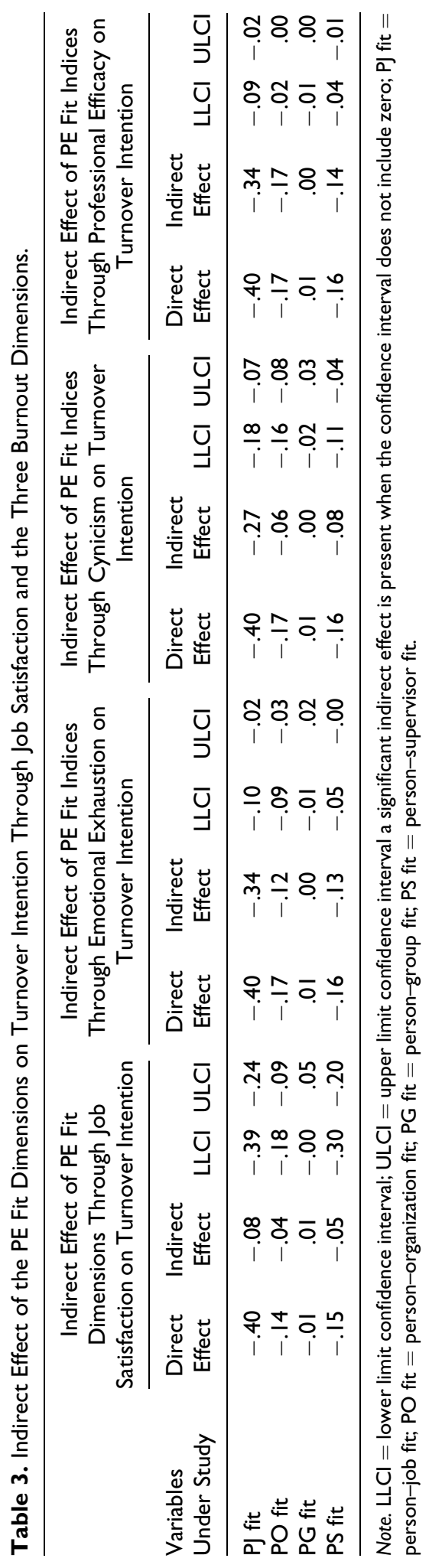


Mediation analysis indicated that PJ fit, PO fit, and PS fit make an independent contribution to turnover intention, even with $\mathrm{EE}$ and $\mathrm{CY}$ as mediators. These partial mediation effects were confirmed when testing the indirect effect (see Table 3) with significant indirect effects of PJ fit, PO fit, and PS fit on turnover intention through EE and CY. We can thus conclude that EE and CY have partial mediation effects between PJ fit, PO fit, PS fit, and turnover intention. Concerning professional efficacy as mediator variable, results indicated that professional efficacy partially mediated the relationship between PJ fit, PS fit, and turnover intention. This partial mediation effect was confirmed when testing the indirect effect (see Table 3). On the contrary, no mediation through professional efficacy was apparent for PO fit and PG fit on turnover intention.

To summarize, results indicated that EE and CY partially mediated the relationships between turnover intentions the three other dimensions of fit: PJ fit, PO fit, and PS fit. Professional efficacy partially mediated the relationship between turnover intention and two PE fit dimensions: PJ fit and PS fit. For PG fit, results did not support the hypothesis. Thus, Hypothesis 3 was partially supported.

\section{Discussion}

$\mathrm{PE}$ fit is considered as a multidimensional construct and has recently been developed and operationalized with four dimensions: PJ fit, PO fit, PG fit, and PS fit (Chuang et al., 2016; Kristof-Brown et al., 2005). However, most of previous studies did not include simultaneously the four dimensions of PE fit to predict work-related outcomes. Thus, the first aim of our study was to use a recent comprehensive assessment of the PE fit dimensions and to analyze their respective relationships with burnout, job satisfaction, and turnover intention. While the PE fit concept has been mostly investigated with the notions of PJ fit and PO fit (Kristof-Brown et al., 2005), our results contribute to the literature by pointing out the relevance of considering the four dimensions of PE fit to better understand work-related outcomes. Indeed, according to the findings, a good match between the individual and his or her job, organization, group, and supervisor appears important to promote job satisfaction, prevent employees from burnout, and limit turnover intention. Our results were in line with the previous findings of Chuang et al. (2016) that showed significant associations between the four PE fit dimensions, job satisfaction, and job performance. The contribution of the current study was to reexamine these associations in a different cultural context and extending the findings by including other relevant work-related outcomes, that is, burnout and turnover intention.

In addition to correlation analysis, the relative impacts of these four dimensions on the work-related outcomes were analyzed through regression analysis. Results suggested that job satisfaction, burnout, and turnover intention were mostly explained by PJ fit, PO fit, and PS fit and to a lesser extent by PG fit. These results differ from Chuang et al.'s (2016) findings that indicated that job satisfaction and turnover intention were explained by all four dimensions of PE fit, including PG fit. One possible explanation for these results could be related to our occupationally heterogeneous sample. Indeed, while each participant had to be included in a working team to participate in the study, working in team can have a different meaning for each occupation. A good PG fit may not be equally important for each occupation, depending for instance on the interdependency of employees in their work, and as such may be less influential for work-related outcomes in comparison to the other fit dimensions. Furthermore, the different findings could be related to the different cultural context of the sample. Chuang et al.'s study seems to be conducted on a Taiwanese sample, with a more collectivist culture than our French sample. In a collectivistic culture, the fit with the group is likely to play a more important role than in an individualist culture. However, these are tentative explanations, and future research could further explore the relationship between PG fit and work-related outcomes among different occupational groups and cultural samples.

The second aim of the study was to gain more insight regarding the process from PE fit to turnover intention, examining the potentially mediating effect of burnout and job satisfaction. The present study 
found evidence for indirect effects of three of the four PE fit on turnover intention through burnout and job satisfaction. Only PG fit did not exert its effects on turnover intention, neither directly nor indirectly via job satisfaction or burnout. Job satisfaction was found to be a total mediator of the effects of PJ fit, PO fit, and PS fit on turnover intention. Moreover, EE and CY partially mediated the relationships between these three fit dimensions and turnover intention. Professional efficacy partially mediated the relationship between two PE fit dimensions, PJ fit and PS fit, and turnover intention. As such, the process seems to be that PE fit predicted turnover intention though job satisfaction and burnout: PJ fit, PO fit, and PS fit were related to high scores of job satisfaction and low scores of $\mathrm{EE}$ and $\mathrm{CY}$ which in turn limit turnover intention. These findings were in line with the health impairment process and the motivational process described by Bakker, Demerouti, and Schaufeli (2003) and Miraglia and Johns (2016). To conclude, the findings of the current study highlight the importance of a good PE fit for work-related outcomes.

Concerning the practical implications, organizations would benefit from integrating this insight in the selection process of new personnel. A first step would be to create a good description of the characteristics of the job, the organization, the supervisor, and the work group in terms of values and goals. On this basis, one could determine in advance to which extent an applicant matches to the job, organization, work group, and supervisor and take this into account into the decision to hire a specific employee. Incorporating this PE fit aspect more explicitly in the selection process would benefit both the applicant and the organization, as it prevents PE misfit and its negative consequences. To get a good impression from one's values/goals before one enters a job, the construction of a valid and reliable questionnaire or interview method to assess this would be required. Furthermore, it would be worthwhile to assess PE fit in employees on a regular basis and to take these results into account in striving for the creation of a better PE fit in their current job, and guide them in their future career decisions. In any cases, although PE fit deals with the adjustment of individuals, we agree with Caplan (1987) by suggesting that adjustment of the work environment (organization, job, team, and supervisor) is also a worthwhile avenue to establish PE fit. In other words, an organizational perspective should be also recommended, as without systemic programs, individual changes may be short-lived.

\section{Strengths and Limitations}

Our study has several strengths: It included a large multioccupation sample, and valid and reliable measures were used for PE fit as well as the work-related outcomes. However, some limitations should be taken into account in interpreting its results. Indeed, as we could only control for a limited number of background variables, the data were limited with regard to background variables that could be potential confounders. Future research could assess these more comprehensively to rule out potentially confounding effects. Another limitation of our study was its reliance on self-report measures to assess both the predictors and the outcomes. As a result, our findings might be influenced by common method bias. For future research, including also more objective assessment of the work-related outcomes (e.g., absenteeism, actual turnover) would be an asset. Moreover, as a crosssectional design was used, we should be cautious in interpreting the causality of the findings of this research. The next step would be to repeat our study in a longitudinal design, to further substantiate the causal interpretation. Indeed, burnout was described in most studies as a result of an individual's fit perception, but the reciprocal relationship could be envisaged as pointed out by Gabriel, Diefendorff, Chandler, Moran, and Greguras (2014). However, Edwards and Shipp (2007) summarized some of the most salient findings in this area and concluded that global fit is most frequently considered a predictor of occupational health and well-being and not as a consequence. Thus, our proposed model was in line with theory and empirical findings and the present study supported the direct and indirect effects of PE fit on job satisfaction, reduced burnout, and turnover intention. 


\section{Declaration of Conflicting Interests}

The author(s) declared no potential conflicts of interest with respect to the research, authorship, and/or publication of this article.

\section{Funding}

The author(s) received no financial support for the research, authorship, and/or publication of this article.

\section{References}

Agho, A. O., Price, J. L., \& Mueller, C. W. (1992). Discriminant validity of measures of job satisfaction, positive affectivity and negative affectivity. Journal of Occupational and Organizational Psychology, 65, 185-195. Retrieved from https://doi.org/10.1111/j.2044-8325.1992.tb00496.x

Bakker, A. B., \& Demerouti, E. (2007). The job demands-resources model: State of the art. Journal of Managerial Psychology, 22, 309-328.

Bakker, A. B., Demerouti, E., De Boer, E., \& Schaufeli, W. B. (2003). Job demands and job resources as predictors of absence duration and frequency. Journal of Vocational Behavior, 62, 341-356.

Bakker, A. B., Demerouti, E., \& Schaufeli, W. B. (2002). Validation of the maslach burnout inventory-General survey: An internet study. Anxiety, Stress and Coping, 15, 245-260.

Baron, R. M., \& Kenny, D. A. (1986). The moderator-mediator variable distinction in social psychological research: Conceptual, strategic, and statistical considerations. Journal of Personality and Social Psychology, 51, 1173.

Cable, D. M., \& DeRue, D. S. (2002). The convergent and discriminant validity of subjective fit perceptions. The Journal of Applied Psychology, 87, 875-884. Retrieved from https://doi.org/10.1037/0021-9010.87.5.875

Caplan, R. D. (1987). Person-environment fit theory and organizations: Commensurate dimensions, time perspectives, and mechanisms, Journal of Vocational Behavior, 31, 248-267.

Cheung, F. Y. L., \& Tang, C. S. K. (2007). The influence of emotional dissonance and resources at work on job burnout among Chinese human service employees. International Journal of Stress Management, 14, $72-87$. Retrieved from https://doi.org/10.1037/1072-5245.14.1.72

Chuang, A., Shen, C. T., \& Judge, T. A. (2016). Development of a multidimensional instrument of personenvironment fit: The perceived person-environment fit scale (PPEFS). Applied Psychology: An International Review, 65, 66-98. Retrieved from https://doi.org/10.1017/CBO9781107415324.004

Cummings, T. G., \& Cooper, C. L. (1979). A cybernetic framework for studying occupational stress. Human Relations, 32, 395-418.

Edwards, J. R., \& Billsberry, J. (2010). Testing a multidimensional theory of person-environment fit. Journal of Managerial Issues, 22, 476-493.

Edwards, J. R., \& Cooper, C. L. (1990). The person-environment fit approach to stress: Recurring problems and some suggested solutions. Journal of Organizational Behavior, 11, 293-307.

Edwards, I. R., \& Shipp, A. I. (2007). The relationship between person-environment fit and outcomes: An integrative. Perspectives on Organizational Fit, 209. Retrieved from http://doi.org/10.4324/9780203810026

Fouquereau, E., \& Rioux, L. (2002). Elaboration de l'Echelle de satisfaction de vie professionnelle (ESVP) en langue française: une démarche exploratoire [Development of a French scale of professional life satisfaction: an exploratory study]. Canadian Journal of Behavioural Science [Revue Canadienne Des Sciences Du Comportement], 34, 210-215.

French, J. R. P., Rodgers, W., Cobb, S., Coelho, G. V., Hamburg, D. A., \& Adams, J. E. (1974). Coping and adaptation.

French, J. R., Caplan, R. D., \& Van Harrison, R. (1982). The mechanisms of job stress and strain (Vol. 7). Chichester (Sussex); New York: J. Wiley. 
Gabriel, A. S., Diefendorff, J. M., Chandler, M. M., Moran, C. M., \& Greguras, G. J. (2014). The dynamic relationships of work affect and job satisfaction with perceptions of fit. Personnel Psychology, 67, 389-420. Retrieved from https://doi.org/10.1111/peps. 12042

Griffin, M. L., Hogan, N. L., Lambert, E. G., Tucker-Gail, K. A., \& Baker, D. N. (2010). Job involvement, job stress, job satisfaction, and organizational commitment and the burnout of correctional staff. Criminal Justice and Behavior, 37, 239-255.

Han, S. J., Bonn, M. A., \& Cho, M. (2016). The relationship between customer incivility, restaurant frontline service employee burnout and turnover intention. International Journal of Hospitality Management, 52 , 97-106.

Harrison, R. V. (1978). Person-environment fit and job stress. In C. L. Cooper \& R. Payne (Eds.), Stress at work (pp. 175-205). New York, NY: Wiley.

Hayes, A. F. (2009). Beyond Baron and Kenny: Statistical mediation analysis in the new millennium. Communication Monographs, 76, 408-420.

Hinkin, T. R., \& Tracey, J. B. (2000). The cost of turnover: Putting a price on the learning curve. Cornell Hotel and Restaurant Administration Quarterly, 41, 14-21. Retrieved from https://doi.org/10.1177/ 001088040004100313

Holland, J. L. (1985). The self-directed search: Professional manual. Odessa, FL: PAR.

Jansen, K. J., \& Kristof-brown, A. L. (2006). Toward a multidimensional theory of person-environment fit. Journal of Managerial Issues, 18, 193-212.

Katzell, R. A. (1964). Personal values, job satisfaction, and job behavior. In Borow, H. (Ed.), Man in a world of work (pp. 341-363). Boston: Houghton Mifflin Company.

Kim, T. Y., Aryee, S., Loi, R., \& Kim, S. P. (2013). Person-organization fit and employee outcomes: Test of a social exchange model. The International Journal of Human Resource Management, 24, 3719-3737. Retrieved from http://dx.doi.org/10.1080/09585192.2013.781522

Kim, H., \& Stoner, M. (2008). Burnout and turnover intention among social workers: Effects of role stress, job autonomy and social support. Administration in Social Work, 32, 5-25.

Kraemer, T., \& Gouthier, M. H. J. (2014). How organizational pride and emotional exhaustion explain turnover intentions in call centers: A multi-group analysis with gender and organizational tenure. Journal of Service Management, 25, 125-148.

Kristof-Brown, A. L. (2000). Perceived applicant fit: Distinguishing between recruiters' perceptions of person-job and person-organization fit. Personnel Psychology, 53, 643-671. Retrieved from https://doi.org/10.1111/j. 1744-6570.2000.tb00217.x

Kristof-Brown, A. L., \& Guay, R. P. (2011). Person-environment fit. In S. Zedeck (Ed.), APA handbook of industrial and organizational psychology, Vol. 3: Maintaining, expanding, and contracting the organization (pp. 3-50). Washington, DC: American Psychological Association. doi:10.1037/12171-001

Kristof-Brown, A. L., Jansen, K. J., \& Colbert, A. E. (2002). A policy-capturing study of the simultaneous effects of fit with jobs, groups, and organizations. The Journal of Applied Psychology, 87, 985-993. Retrieved from https://doi.org/10.5465/APBPP.2001.27461493

Kristof-Brown, A. L., \& Stevens, C. K. (2001). Goal congruence in project teams: Does the fit between members' personal matery and performance goals matter? Journal of Applied Psychology, 86, 1083-1095. Retrieved from https://doi.org/10.1037/0021-9010.86.6.1083

Kristof-brown, A. L., Zimmerman, R. D., \& Johnson, E. C. (2005). Consequences of individuals' fit at work: A meta-analysis of person-job, person-organization, person-group, and person-supervisor fit. Personnel Psychology, 58, 281-342.

Lauver, K. J., \& Kristof-Brown, A. (2001). Distinguishing between employees' perceptions of person-job and person-organization fit. Journal of Vocational Behavior, 59, 454-470. Retrieved from https://doi.org/10. 1006/jvbe.2001.1807

Lazarus, R. S., \& Folkman, S. (1984). Coping and adaptation. The handbook of behavioral medicine (pp. 282-325). New York: Guilford. 
Lee, R. T., \& Ashforth, B. E. (1993). A further examination of managerial burnout: Toward an integrated model. Journal of Organizational Behavior, 14, 3-20. Retrieved from https://doi.org/10.1002/job.4030140103

Leiter, M. P., \& Maslach, C. (2009). Nurse turnover: The mediating role of burnout. Journal of Nursing Management, 17, 331-339. Retrieved from https://doi.org/10.1111/j.1365-2834.2009.01004.x

Lewin, K. (1951). Field theory in social science. New York, NY: Harper.

Locke, E. A. (1976). The nature and causes of job satisfaction. In M. D. Dunnette (Ed.), Handbook of industrial and organizational psychology (pp. 1297-1347). Chicago: Rand McNally.

Lok, P., \& Crawford, J. (2001). Antecedents of organizational commitment and the mediating role of job satisfaction. Journal of Managerial Psychology, 16, 594-613.

Lu, A. C. C., \& Gursoy, D. (2016). Impact of job burnout on satisfaction and turnover intention: Do generational differences matter?. Journal of Hospitality \& Tourism Research, 40, 1-26. Retrieved from https://doi.org/10. $1177 / 1096348013495696$

Maslach, C., \& Jackson, S. E. (1981). The measurement of experienced burnout. Journal of Organizational Behavior, 2, 99-113. Retrieved from https://doi.org/10.1002/job.4030020205

McCulloch, M. C., \& Turban, D. B. (2007). Using person-organization fit to select employees for high-turnover jobs. International Journal of Selection and Assessment, 15, 63-71. Retrieved from https://doi.org/10.1111/j. 1468-2389.2007.00368.x

McGrath, J. E. (1976). Stress and behavior in organizations. Handbook of industrial and organizational psychology (pp. 1351-1396). Chicago: Rand-McNally.

Miraglia, M., \& Johns, G. (2016). Going to work ill: A meta-analysis of the correlates of presenteeism and a dual-path model. Journal of Occupational Health Psychology, 21, 261.

Mobley, W. H., Horner, S. O., \& Hollingsworth, A. T. (1978). An evaluation of precursors of hospital employee turnover. Journal of Applied Psychology, 63, 408.

Murray, H. (1938). Explorations in personality, New York, NY: Oxford University Press.

O'Reilly, C. A., Chatman, J., \& Caldwell, D. F. (1991). Oreilly1991.pdf. The Academy of Management Journal, 34, 487-516.

Ostroff, C., Shin, Y., \& Kinicki, A. J. (2005). Multiple perspectives of congruence: Relationships between value congruence and employee attitudes. Journal of Organizational Behavior, 26, 591-623. Retrieved from https:// doi.org/10.1002/job.333

Pyhältö, K., Pietarinen, J., \& Salmela-Aro, K. (2011). Teacher-working-environment fit as a framework for burnout experienced by Finnish teachers. Teaching and Teacher Education, 27, 1101-1110.

Schaufeli, W. B., \& Bakker, A. B. (2004). Job demands, job resources, and their relationship with burnout and engagement: A multi-sample study. Journal of Organizational Behavior, 25, 293-315. Retrieved from https://doi.org/10.1002/job.248

Schaufeli, W. B., Leiter, M. P., Maslach, C., \& Jackson, S. E. (1996). The MBI-general survey. In C. Maslach, S. E. Jackson, \& M. Leiter (Eds.), Maslach burnout inventory (3rd ed., pp. 19-26). Palo Alto, CA: Consulting Psychologists Press.

Scherer, L. L., Allen, J. A., \& Harp, E. R. (2016). Grin and bear it: An examination of volunteers' fit with their organization, burnout and spirituality. Burnout Research, 3, 1-10. Retrieved from https://doi.org/10.1016/j. burn.2015.10.003

Seong, J. Y., \& Kristof-Brown, A. L. (2012). Testing multidimensional models of person-group fit. Journal of Managerial Psychology, 27, 536-556.

Shanafelt, T. D., West, C. P., Sloan, J. A., Novotny, P. J., Poland, G. A., Menaker, R., .. Dyrbye, L. N. (2009). Career fit and burnout among academic faculty. Archives of Internal Medicine, 169, 990.

Tett, R. P., \& Meyer, J. P. (1993). Job satisfaction, organizational commitment, turnover intention, and turnover: Path analyses based on meta-analytic findings. Personnel Psychology, 46, 259-293. Retrieved from https:// doi.org/10.1111/j.1744-6570.1993.tb00874.x

Tong, J., Wang, L., \& Peng, K. (2015). From person-environment misfit to job burnout: Theoretical extensions. Journal of Managerial Psychology, 30, 169-182. 
Van Vianen, A. E. M. (2000). Person-organization fit: The match between newcomers' and recruiters' preferences for organizational cultures. Personnel Psychology, 53, 113-149.

Vancouver, J. B., \& Schmitt, N. W. (1991). An exploratory examination of person-organization fit: Organizational goal congruence. Personnel Psychology, 44, 333-352. Retrieved from https://doi.org/10.1017/ CBO9781107415324.004

Wang, M., Zhan, Y., McCune, E., \& Truxillo, D. (2011). Understanding newcomers' adaptability and workrelated outcomes: Testing the mediating roles of perceived P-E fit variables. Personnel Psychology, 64, 163-189. Retrieved from https://doi.org/10.1111/j.1744-6570.2010.01205.x

Wheeler, A. R., Buckley, M. R., Halbesleben, J. R., Brouer, B., \& Ferris, G. R. (2005). The elusive criterion of fit revisited: Toward an integrative theory of multidimensional fit. In J. J. Martocchio (Ed.), Research in personnel and human resources management (Vol. 24, pp. 265-304). New York, NY: Elsevier Science/JAI Press. Retrieved from https://doi.org/10.1017/CBO9781107415324.004

Wheeler, A. R., Gallagher, V. C., Brouer, R. L., \& Sablynski, C. J. (2007). When person-organization (mis)fit and (dis)satisfaction lead to turnover the moderating role of perceived job mobility. Journal of Managerial Psychology, 22, 203-219. Retrieved from https://doi.org/10.1108/02683940710726447

Wright, T. A., \& Cropanzano, R. (1998). Emotional exhaustion as a predictor of job performance and voluntary turnover. Journal of Applied Psychology, 83, 486-493. Retrieved from https://doi.org/10.1037/0021-9010. 83.3.486

\section{Author Biographies}

Marie Andela received her $\mathrm{PhD}$ in 2014 from the University of Franche-comté in France. She is currently working as an assistant professor at the University of Bordeaux. Her teaching and research focus on work and organizational psychology: occupational health, emotion regulation, emotional dissonance, burnout, and employee well-being. In her leisure time, she enjoys outdoor sports as climbing and hiking.

Margot van der Doef received her PhD in 2000 from the University of Leiden in the Netherlands and is currently an assistant professor at the Health, Medical, and Neuropsychology unit of the Institute of Psychology at this university. Her focus in research and teaching is on occupational health psychology. Her research interests include quality of work and employee health and well-being, chronic illness at work, and the development, implementation, and evaluation of worksite health promotion interventions. In her leisure time, she enjoys hiking and reading. 